$\begin{array}{llll}\begin{array}{l}\text { Sathishkumar Ramalingam, MD } \\ \text { Lovelace Medical Center, Albuquerque, NM }\end{array} & \begin{array}{l}\text { Harkesh Arora, MD } \\ \text { Lovelace Medical Center, Albuquerque, NM }\end{array} & \begin{array}{l}\text { Susan Lewis, MD } \\ \text { Lovelace Medical Center, Albuquerque, NM }\end{array} & \begin{array}{l}\text { Kulothungan Gunasekaran, MD } \\ \text { Pulmonary and Critical Care, Bridgeport } \\ \text { Hospital, Bridgeport, CT }\end{array} \\ \begin{array}{l}\text { Maheswari Muruganandam, MD } \\ \text { University of New Mexico, Albuquerque, NM }\end{array} & \begin{array}{l}\text { Sivakumar Nagaraju, MD } \\ \text { Lovelace Medical Center, Albuquerque, NM }\end{array} & \begin{array}{l}\text { Priyesh Padmanabhan, MD } \\ \text { Unity Point Cardiology, Des Moines, IA }\end{array}\end{array}$

\title{
COVID-19 vaccine-induced cellulitis and myositis
}

\section{The patient had no history of allergies to medications or of adverse reactions to vaccinations previously}

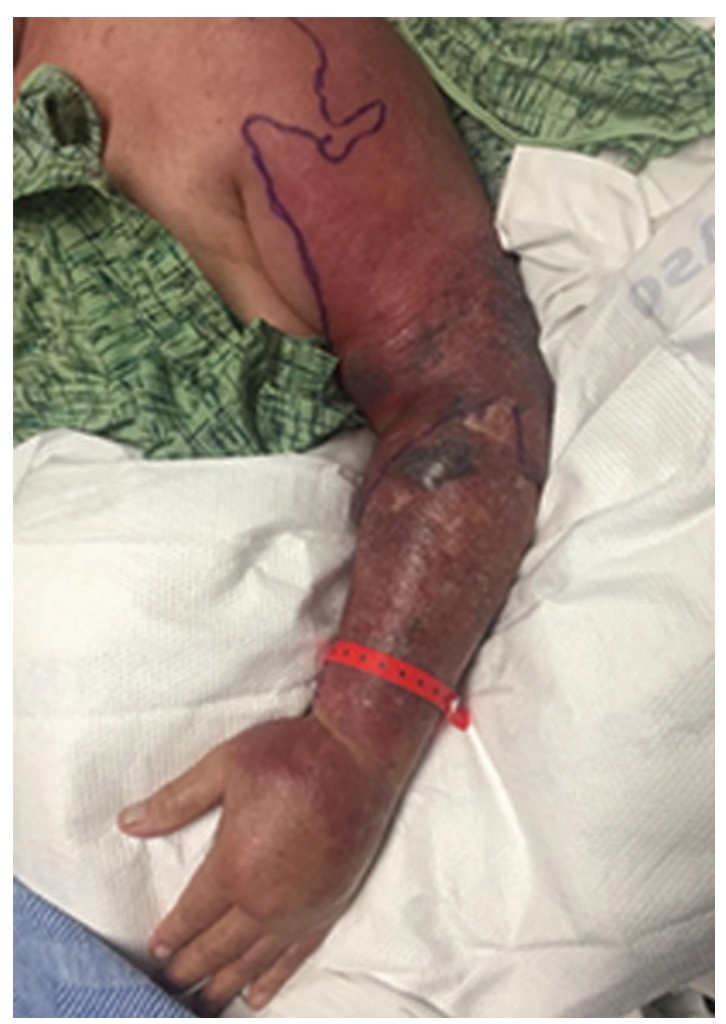

Figure 1. Erythema and swelling of the left upper extremity at presentation.

\footnotetext{
N 8I-yeAR-Old MAN PRESENTEd to the hospital with swelling, pain, and redness in the left arm that had started after he received his second dose of a messenger RNA (mRNA) vaccine. He had no history of allergies to medications and has had no adverse reactions to vaccinations in the past.

He had received the first dose of a messenger RNA (mRNA) COVID-19 vaccine in the right arm 4 weeks ago, and he noticed redness doi:10.3949/ccjm.88a.21038
}

and pain at the injection site, which resolved within 2 days. But 4 weeks later, after receiving the second dose of the mRNA vaccine, this time on the left arm, he noticed redness and pain at the injection site the following day. The redness and swelling continued to increase, involving the whole left arm and shoulder.

His medical history included Parkinson disease, hypertension, paroxysmal atrial fibrillation, and giant cell arteritis, for which he was taking prednisone and tocilizumab. His blood pressure was $146 / 80 \mathrm{~mm} \mathrm{Hg}$, temperature $97.2^{\circ} \mathrm{F}\left(36.2^{\circ} \mathrm{C}\right)$, and heart rate 108 beats per minute. Physical examination revealed extensive erythema and tenderness involving the left upper extremity from the shoulder to the distal arm (Figure 1).

Laboratory testing revealed the following:

- White blood cell count $5 \times 10^{9} / \mathrm{L}$ (reference range 4-11 109/L)

- Creatine kinase $236 \mathrm{U} / \mathrm{L}$ (reference range 35-232 U/L)

- Lactic acid $3.1 \mathrm{mmol} / \mathrm{L}$ (reference range $0.4-2 \mathrm{mmol} / \mathrm{L}$ )

- Aldolase 20.9 U/L (reference range 1.5$8.1 \mathrm{U} / \mathrm{L})$

- C-reactive protein $6.3 \mathrm{mg} / \mathrm{dL}$ (reference range $0.0-0.9 \mathrm{mg} / \mathrm{dL})$.

Computed tomography (CT) of the left upper extremity showed proximal cellulitis and myositis of the deltoid muscle, and fasciitis was not excluded due to multicompartment findings. Magnetic resonance imaging (MRI) revealed diffuse cellulitis and myositis of the deltoid and supraspinatus muscle concerning for myositis due to mRNA COVID-19 vaccine (Figure 2).

The patient was treated with intravenous vancomycin and piperacillin-tazobactam, and 


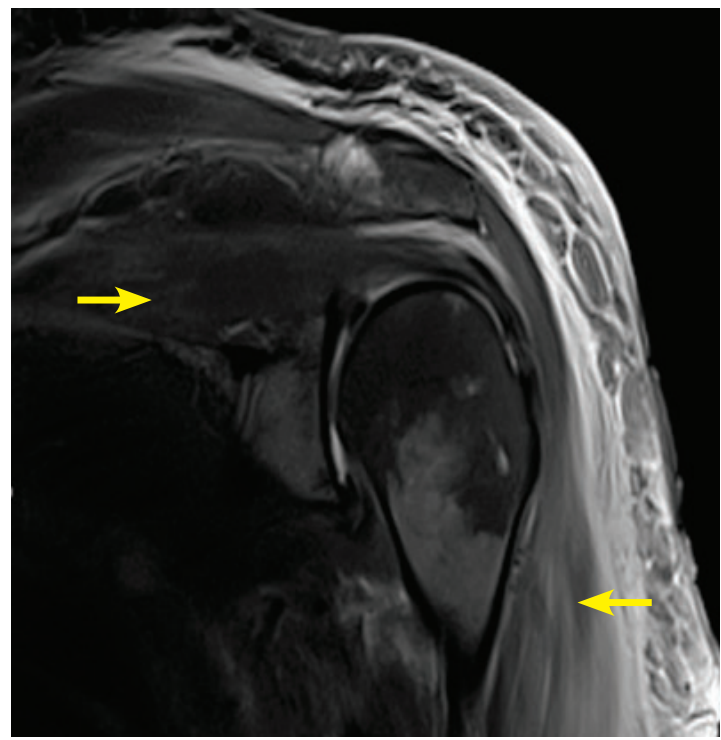

Figure 2. Magnetic resonance imaging without contrast showing diffuse soft-tissue edema (arrows) consistent with cellulitis and myositis of the deltoid and supraspinatus muscle.

methylprednisolone $40 \mathrm{mg}$ once a day, but the erythema and swelling of the left arm worsened, and on day 3 of hospitalization, he underwent local incision and drainage, which showed extensive edema without necrosis. Gram staining was negative for bacteria, and blood and wound culture did not grow any bacteria.

On hospital day 4, repeat laboratory testing showed a creatine kinase level of $98 \mathrm{U} / \mathrm{L}$ and an aldolase level of $10.3 \mathrm{U} / \mathrm{L}$. The swelling and redness of the left upper extremity improved (Figure 3), intravenous antibiotics were stopped, oral prednisolone $4 \mathrm{mg}$ was started, and the patient was discharged on hospital day 7 .

\section{A RANGE OF REACTIONS TO mRNA COVID-19 VACCINE}

The mRNA COVID-19 vaccine is a lipid nanoparticle-encapsulated, nucleoside-modified mRNA vaccine that encodes the prefusion spike glycoprotein of the SARS-CoV-2 virus responsible for COVID-19. ${ }^{1}$ Local reactions include mild to moderate pain at the injection site, and systemic side effects like fatigue, headache, and fever have been common after the second dose. ${ }^{2}$ Immediate reactions

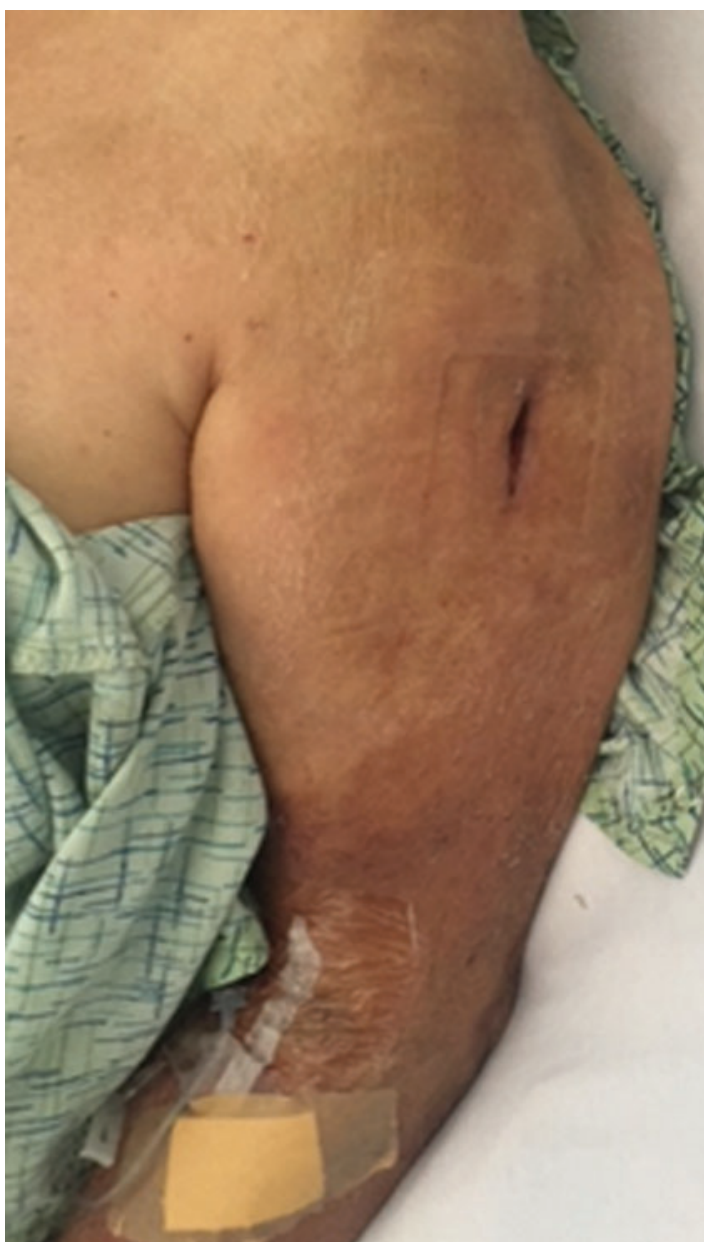

Figure 3. Improvement of the swelling and erythema on hospital day 7.

to mRNA COVID-19 vaccine like local pain, redness, and swelling occur within 2 to 3 days, and delayed injection reactions including erythema, induration, and tenderness occur after 5 days. $^{3}$ Infection at the injection site can happen due to contaminated needles. ${ }^{4}$ Local reactions due to the vaccine can be treated with a cold compress, analgesics, and antihistamine.

The CT and MRI findings in this patient were consistent with cellulitis and myositis, and an elevated aldolase suggested damaged muscle cells in this setting, ${ }^{5}$ although aldolase is not a specific muscle cell marker. Immediate hypersensitivity reactions including itching, flushing, urticaria, angioedema, and hypotension are immunoglobin $\mathrm{E}(\mathrm{IgE})$-mediated allergic reactions that usually begin within minutes of administrating vaccines. Hypersensitivity reactions after the second dose of
The exact mechanism of cellulitis and myositis due to mRNA COVID-19 vaccines is unknown and requires further investigation 
mRNA COVID-19 vaccine may be due to the immune response after the first dose. ${ }^{3}$

Delayed large local reactions to mRNA COVID-19 vaccine may be due to delayedtype or T-cell-mediated hypersensitivity, with perivascular and perifollicular lymphocytic infiltrates on skin biopsy. ${ }^{6}$ The Arthus reaction, a type III immune complex-mediated hypersensitivity reaction, in which antibody-antigen complexes are deposited in the blood vessel causing acute inflammation and local skin necrosis, have been reported after tetanus, diphtheria, and acellular pertussis vaccine adminis- tration. ${ }^{7}$ There have been reports of extensive vaccine-related limb-swelling involving the entire extremity and myositis. ${ }^{8,9}$ Myositis has been reported after vaccination with live-attenuated measles, mumps, and rubella vaccine, diphtheria and tetanus vaccine, hepatitis B vaccine, and influenza and $\mathrm{H} 1 \mathrm{~N} 1$ vaccines. ${ }^{10}$ The exact mechanism of cellulitis and myositis due to the mRNA COVID-19 vaccine is unknown and requires further investigation.

\section{DISCLOSURES}

The authors report no relevant financial relationships which, in the context of their contributions, could be perceived as a potential conflict of interest.

\section{REFERENCES}

1. Polack FP, Thomas SJ, Kitchin N, et al. Safety and efficacy of the BNT162b2 mRNA COVID-19 vaccine. N Engl J Med 2020; 383(27):2603-2615. doi:10.1056/NEJMoa2034577

2. Jackson LA, Anderson EJ, Rouphael NG, et al. An mRNA vaccine against SARS-CoV-2-preliminary report. N Engl J Med 2020; 383(20):1920-1931. doi:10.1056/NEJMoa2022483

3. Johnston MS, Galan A, Watsky KL, Little AJ. Delayed localized hypersensitivity reactions to the Moderna COVID-19 vaccine: a case series. JAMA Dermatol 2021; 157(6):716-720.

doi:10.1001/jamadermatol.2021.1214

4. Miller MA, Pisani. E. The cost of unsafe injections. Bull World Health Organ 1999; 77(10):808-811. pmid:10593028

5. Casciola-Rosen L, Hall JC, Mammen AL, Christopher-Stine L, Rosen A. Isolated elevation of aldolase in the serum of myositis patients: a potential biomarker of damaged early regenerating muscle cells. Clin Exp Rheumatol 2012; 30(4):548-553. pmid:22703875

6. Blumenthal KG, Freeman EE, Saff RR, et al. Delayed large local reac- tions to mRNA-1273 vaccine against SARS-CoV-2. N Engl J Med 2021; 384(13):1273-1277. doi:10.1056/NEJMc2102131

7. Pool V, Mege L, Abou-Ali A. Arthus reaction as an adverse event following Tdap vaccination. Vaccines (Basel) 2020; 8(3):385. doi:10.3390/vaccines8030385

8. Woo EJ, Burwen DR, Gatumu SN, Ball R; Vaccine Adverse Event Reporting System Working Group. Extensive limb swelling after immunization: reports to the Vaccine Adverse Event Reporting System. Clin Infect Dis 2003; 37(3):351-358. doi:10.1086/375820

9. Polat AV, Bekci T, Dabak N, Ulu EM, Selcuk MB. Vaccine-induced myositis with intramuscular sterile abscess formation: MRI and ultrasound findings. Skeletal Radiol 2015; 44(12):1849-1852. doi:10.1007/s00256-015-2242-1

10. Rodriguez-Pintó I, Shoenfeld $Y$. Myositis and vaccines. In: Shoenfeld Y, Agmon-Levin N, Tomljenovic L, eds. Vaccines and Autoimmunity. Hoboken, NJ: Wiley-Blackwell; 2015:349-358.

Address: Sathishkumar Ramalingam, MD, Lovelace Medical Center, 601 Dr. Martin Luther King Jr. Avenue NE, Albuquerque, NM 87102; sathishmed@gmail.com 